\title{
Mathematical modeling and glaucoma: the need for an individualized approach to risk assessment
}

Alice Chandra Verticchio Vercellin ${ }^{1,2}$, Alon Harris ${ }^{1}$, Jareau Vance Cordell ${ }^{1}$, Thai Do ${ }^{1}$, James Moroney ${ }^{3}$, Aditya Belamkar ${ }^{1}$, Brent Siesky ${ }^{1}$

${ }^{1}$ Department of Ophthalmology, Indiana University School of Medicine, Indianapolis, IN, USA; ${ }^{2}$ University Eye Clinic, IRCCS Policlinico San Matteo, Pavia, Italy; ${ }^{3}$ Michigan State University School of Medicine, Grand Rapids, MI, USA

\section{Abstract}

Primary open-angle glaucoma is a chronic optic neuropathy characterized by retinal ganglion cell loss and subsequent visual field impairment. Elevated intraocular pressure remains the only treatable and modifiable risk factor and vascular impairment has been demonstrated in glaucomatous patients. New research has uncovered varying and often contradictory data suggesting more than just a casual correlation with ethnicity, diabetes, gender, obesity and age. Little is known about each variables' contribution to the etiology of glaucoma and how their presence or absence with other risk factors potentiate or reduce an individual's overall risk. The realization that glaucoma is more than a simple, binary disease necessitates a next-generation mathematical model with the capability to integrate individual patient characteristics and clinical risk factors to predict its formation and progression.

Key words: blood flow, disease progression, mathematical modeling, primary open-angle glaucoma, risk factors

Correspondence: Alon Harris, MS, PhD, FARVO, Director of Clinical Research, Lois Letzter Professor of Ophthalmology, Professor of Cellular and Integrative Physiology, Department of Ophthalmology, Indiana University School of Medicine, 1160 West Michigan Street, Indianapolis, IN 46202, USA. E-mail: alharris@indiana.edu 


\section{Introduction}

Glaucoma is the second leading cause of blindness. ${ }^{1-3}$ Primary open-angle glaucoma (POAG) is characterized by progressive retinal ganglion cell death and irreversible visual field loss. To date, intraocular pressure (IOP) is the only modifiable risk factor. ${ }^{4}$ Despite aggressive medical and surgical treatment, a high percentage of individuals with normal IOP continue to experience disease progression and visual field loss. ${ }^{1,5-9}$ The observed progression of POAG despite aggressive IOP management suggests that glaucoma is a multifactorial disease with inadequate surveillance and management. ${ }^{10}$ Previous clinical studies have shown changes in blood flow in retinal, choroidal and retrobulbar circulations in POAG. ${ }^{11-12}$ Over the last few decades, additional risk factors for POAG have been discovered which include advanced age, ethnic background, family history of glaucoma, decreased central corneal thickness (CCT), higher vertical cup-to-disk ratios (CDR) of the optic disc, and increased pattern standard deviation (PSD) values on Humphrey automated perimeter at baseline. ${ }^{13}$ Other patient characteristics including diabetes mellitus (DM), gender, and obesity have been correlated with variation in glaucoma development and differences in glaucoma progression. The mechanisms by which these factors contribute to POAG pathophysiology are still largely unknown. It remains unclear which of these factors are causes or consequences of the disease and whether combinations of different factors yield similar risk for POAG. Without significant advancement in the current understanding of the pathogenesis of glaucoma, the impact of this irreversible blindness on the quality of life worldwide will continue unabated. Due to the heterogeneity of the pathophysiology of glaucoma, it is critical to develop a mathematical model to characterize the probability of glaucoma development and changes in progression based on patient-specific risk factors and known predictive markers of glaucoma development.

\subsection{Aqueous humor physiology}

Aqueous humor is produced by the non-pigmented epithelium of the ciliary body in the posterior chamber. From there, it flows into the anterior chamber and exits through the trabecular meshwork and Schlemm's canal or the uveoscleral pathway. ${ }^{14}$ This traditional model has influenced both our clinical approach and treatment of glaucoma for decades. In highlighting the intrinsically complex interplay of intraocular pressure homeostasis, emerging research in aqueous humor dynamics demonstrates the presence of a third modifiable outflow pathway. ${ }^{15,16}$ This additional outlet involves ocular lymphatics, a tissue previously believed to be absent in the eye, within the ciliary body itself. While serving as a potential target for future pharmacological manipulation, this discovery further emphasizes the need for a robust mathematical model that can be dynamically customized and implemented as our understanding of glaucoma evolves. 
A.C. Verticchio- Vercellin et al.

\subsection{Ophthalmological examination in the clinical practice}

The ophthalmological examination is a standard tool in ascertaining crucial information about the overall condition of the patient. The eye is often the first part of the body involved in systemic diseases; as a consequence, the ophthalmologist is frequently the first specialist to diagnose a systemic pathology. In particular, several ophthalmic clinical measurements have an important relevance in this field. ${ }^{17}$ The assessment of visual acuity can be used as a tool for early diagnosis of diabetic status: a decrease in the visual acuity caused by a myopic shift of the refraction can be for example the first sign of diabetes that causes an increase of the level of the sugar in the aqueous humor. The examination of the fundus oculi, another important part of the ophthalmological examination, can also be informative. In fact, the vessels of the retina represent the only ones in the whole body that can be observed directly and non-invasively by the physician, which can be used to ascertain systemic vessel health. In this sense, the diagnosis and follow up of important systemic conditions, such as diabetes and hypertension, is realized by the periodical examination of the fundus oculi at the slit lamp. Importantly, the retina and the nerve fibers of the optic nerve derived embryological from the neural tube and the eye can be considered as a natural protrusion of the brain. Therefore, neurological disorders can have their first manifestation in the eye. For instance, optic neuritis is frequently the initial sign of multiple sclerosis. Other neurological diseases, such as brain tumors or cerebral ischemia, can be diagnosed with visual field examination, another noninvasive tool that ophthalmologist use in their clinical practice.

In conclusion, important parts of the ophthalmic exam, such as the evaluation of visual acuity, fundus examination through slit lamp and visual field assessment, are noninvasive tools to aid the physician in performing a comprehensive medical evaluation to determine the overall health of an individual.

\subsection{Mathematical modeling and glaucoma}

Mathematical modeling consists of translating 'real-world problems' into mathematical equations whose solutions simulate the behavior of a physical system. ${ }^{18}$ Statistical analysis of experimental and clinical data is one of the most common uses of mathematics in medicine. In the context of glaucoma, mathematical modeling has been used to characterize mechanical response of the optic nerve head (ONH) with variation in IOP, scleral tension and cerebrospinal fluid pressure (CSFP), as well as hemodynamic changes in ocular blood flow and regulation in retinal, choroidal, and $\mathrm{ONH}$ vascular beds. ${ }^{18}$ Several analytical models attempted to characterize glaucoma progression based on biomechanical changes of the eye, such as scleral thickness, retinal nerve fiber layer (RNFL) thickness and visual functional data. ${ }^{19-24}$

In this review, we will summarize the role of various heterogeneous, confounding factors (ethnicity, diabetic status, gender, obesity, and age) in the pathophysiology of glaucoma, including recent results obtained by our research team in a pilot analysis of POAG patients over a five-year period. Therefore, we will demonstrate 
the necessity of comprehensive mathematical modeling capable of predicting the natural course of disease progression, which holds the promise for individualized patient care by incorporating specific characteristics lacking in current models to date.

\section{Materials and methods}

Electronic databases utilized in the search strategy for journal articles included Pubmed, Google Scholar and Web of Science. Journal article inclusion criteria were based on open-angle glaucoma risk factors for the following populations: European descent, African descent, diabetes, gender, obesity and age. The exclusionary criteria implemented included non-African and non-European ancestry and ophthalmic diseases of intraocular pressure etiology other than open-angle glaucoma. Key words used in search strategy consisted of primary open-angle glaucoma, ethnicity, diabetes, gender, obesity, body-mass index, age, intraocular pressure, risk factors, glaucomatous progression, treatment, mathematical model, optic-head morphology, visual acuity, ocular perfusion pressure and capillary blood flow. Articles were also assessed for open-angle glaucoma diagnostic and treatment paradigms in order to the survey the current literature for up to date methodologies and approaches. Search parameters for article publication date were configured to extrapolate the most recent findings.

\subsection{Risk and prognostic factors}

\subsubsection{Ethnicity}

Ethnicity is a known modifier of POAG. ${ }^{1}$ Studies have indicated increased incidence and prevalence of POAG in people of African descent (AD) compared to those of European descent (ED). ${ }^{10,25-27}$ These patients have increased risk of developing POAG at an earlier age and their disease progression is often more rapid. ${ }^{28-31}$ Furthermore, structural differences in persons of $A D$ include thinner corneas, higher percentage of reported DM, high blood pressure and a worse pattern of mean deviation and PSD for standard automated perimetry fields. ${ }^{30,32-35}$ Despite studies demonstrating the differences in the development and disease progression of POAG between persons of $A D$ and $E D$, the mechanisms underlying this disparity have yet been elucidated.

In previous publications, our research group has demonstrated that AD participants with POAG had statistically significant lower retrobulbar blood flow velocities than participants of ED, including lower ophthalmic artery end diastolic velocity, central retinal artery peak systolic velocity, temporal posterior short ciliary arteries peak systolic velocity, and nasal posterior short ciliary arteries peak systolic velocity. ${ }^{36}$ Individuals of AD with POAG have been reported to also have higher systolic and diastolic blood pressures than their ED counterparts, including within 
the aforementioned data set. ${ }^{36-37}$ Although the studies did not focus on causation of these blood pressure differences, the higher systemic blood pressure in the AD cohort with lower localized blood velocity in ocular tissues suggests constriction may be occurring rather than lower delivery force. Whether the systemic and hemodynamic variation in retrobulbar blood flow observed in subjects of $A D$ is due to racial ethnicity alone or in combination with other parameters, such as increased association with DM and systemic hypertension, remains unknown. ${ }^{30,32-35}$

To further clarify the relationship between ethnicity and POAG disease progression, our team analyzed data from a five-year observational study comparing patients of $A D$ and ED. We identified statistically significant differences in the changes from baseline to five years follow-up in the nasal posterior short ciliary arteries end diastolic velocity $(p=0.0430)$ between participants of $A D$ and ED. Furthermore, measurement of retinal capillary blood flow by Heidelberg retinal flowmetry showed an increased area of avascular retinal tissue in subjects of $A D$ ( $p=0.0436$ ) compared to ED. Baseline inferior RNFL thickness assessed by optical coherence tomography was found to be predictive of structural progression in patients of ED ( $p=0.0048)$ but not of $A D(p=0.6955)$, with a statistically significant difference between groups $(p=0.0379)$. The results of previous studies and from our research team suggest that POAG patients of AD have lower retrobulbar blood flow and more retinal capillary dropout associated with their disease progression compared to POAG patients of ED. Whether the observable differences in ocular blood flow between the patient populations is solely dependent on race only or in combination with other parameters remains unclear. The complexity in the heterogeneity of the disease presentation emphasizes the significance of an integrative mathematical model that is capable of incorporating race, in conjunction with other known patient's characteristics, to assist clinicians in predicting patient's specific disease progression.

\subsubsection{Diabetes}

The association between DM and POAG has been widely investigated; however, the underlying pathophysiology remains poorly understood. ${ }^{38}$ Several large-scale population-based cohort studies have reported that DM is a significant risk factor for the development and progression of POAG. ${ }^{39-41}$ While others, including the Rotterdam Study, have shown baseline DM status is not predictive of POAG development at 6.5-year follow-up. ${ }^{42}$ One postulate is that increased CCT in diabetic patients leads to increased IOP, which, in and of itself, is a major risk factor for POAG progression. ${ }^{43}$ There is also evidence that diabetes and elevated IOP together cause increased retinal ganglion cell death. ${ }^{43}$ Diabetes may also lead to increased risk of POAG through dysfunctional optic nerve vessels and oxidative damage. ${ }^{39}$ To further complicate matters, there is a difference in glaucoma development and progression depending on whether the individual has type-1 diabetes (T1DM) or type-2 diabetes (T2DM). Patients with T1DM have 5.94 times greater risk of developing secondary glaucoma 
while patients with T2DM demonstrate a 4.43 times greater risk. ${ }^{45}$ Additionally, POAG is more common in patients with non-proliferative diabetic retinopathy than in patients with pre-proliferative or proliferative diabetic retinopathy. ${ }^{45}$

Emerging evidence suggests that impaired ocular perfusion pressure (OPP) and regulation of retinal blood flow observed in diabetic patients contributes to glaucomatous progression. ${ }^{46}$ Central retinal artery peak systolic velocity is lower in $\mathrm{DM}$, which correlates to reduce OPP. ${ }^{46} \mathrm{~A}$ negative correlation also exists between retrobulbar blood flow and retinal circulation in DM patients but is absent in non-diabetic patients. ${ }^{46}$

As seen in the studies aforementioned, the role of DM in the onset and progression of glaucoma has not been clearly elucidated. Further to the above-mentioned analysis, our research group investigated the role of retrobulbar and capillary blood flow in diabetic glaucoma patients over a 5-year period. In the analysis of retrobulbar blood flow assessed with color Doppler imaging, a statistically significant difference from baseline to five-year follow-up was demonstrated in the resistivity index of the ophthalmic artery $(p=0.0017)$ and central retinal artery $(p=$ 0.0482 ) between patients with DM compared to those without DM. In addition, the evaluation of the capillary blood flow realized by the Heidelberg retinal flowmetry showed that the area of retinal avascularity at baseline was a predictive factor of structural progression of the disease after five years in glaucoma patients with DM $(p=0.0297)$ but not in those without $(p=0.5924)$, with a statistically significant difference between the two groups $(p=0.0352)$.

Knowing the complexity of the correlation between DM and POAG and the contradictory results of the studies mentioned above, a mathematical model able to incorporate the diabetic status of the patient could aid clinicians in the decision making process to diagnose and manage the disease with an individualized approach.

\subsubsection{Gender}

Various bodies of glaucoma research have shown incongruent results with respect to analyzing gender disparities. The Blue Mountain Eye Study showed a higher POAG prevalence among women while the group Rudnicka-Ashby et al. (2006), found male participants were more likely to develop open angle glaucoma. ${ }^{47-48}$ The Framingham and Beaver Dam Eye Studies found that gender was not a risk factor in the development of glaucoma. ${ }^{49-50}$

To date, clear differences in retrobulbar blood flow and its role in glaucoma between men and women have been presented, while others have failed to establish any clear correlation altogether. One study found that men had higher peak systolic velocities, end diastolic velocities, resistive index and pulsatile index (PI) in the ophthalmic artery compared to women. In the same group, women had higher peak systolic velocity, end diastolic velocity, resistive index and $\mathrm{PI}$ in the short posterior ciliary arteries compared to men. Interestingly, these results were 
more significant in the younger groups than in the older groups ${ }^{51}$ Yet another group who measured the hemodynamic parameters of retrobulbar vessels found no statistically significant difference. ${ }^{52}$ In an attempt to unveil the intricacies associated with gender differences, Harris-Yitzhak et al. (2000), showed how young women and postmenopausal women receiving estrogen exhibited reduced resistive indices when compared to postmenopausal women not receiving estrogen. ${ }^{53}$ Younger women showed greater peak systolic velocity and end diastolic velocity in the short posterior ciliary arteries versus both postmenopausal groups. Conversely, another study found no difference in retinal or retrobulbar blow flow measurements in comparing the effects of Raloxifene on postmenopausal women. ${ }^{54}$ Retrobulbar blood vessel caliber analysis in several large studies failed to reveal any differences between males and females. ${ }^{55-56}$ These findings suggest the importance of sex hormones as viable candidates to explain retrobulbar blood flow differences among men and women.

In response to the previous contradictory studies, we recently identified, utilizing color Doppler imaging to measure blood flow velocities in POAG patients, a statistically significant difference between gender in the change from baseline to five-year follow-up in the ophthalmic artery end diastolic velocity $(p=0.0241)$ and central retinal artery resistive index $(p=0.0496)$. In addition, the central retinal artery (CRA) peak systolic velocity (PSV) and end diastolic velocity (EDV) were found to be baseline predictive factors of structural progression in open-angle glaucoma patients after five years in males (CRA PSV: $p=0.0076$; CRA EDV: $p=0.0131$ ), but not females, (CRA PSV: $p=0.5459$; CRA EDV: $p=0.0604$ ) with a statistically significant difference between the two groups (CRA PSV: $p=0.0113$; CRA EDV: $p=0.0020$ ). These results further validate gender as an important characteristic in our ever-evolving glaucoma model and illustrate its capricious nature between men and women. While monitoring the blood flow velocities in the ophthalmic artery of males to quantify and track disease burden was highly significant, no equivalent marker was found in women. The likely mechanism for such varying and confusing study results will likely be revealed when mathematical modeling is capable of simulating the multifactorial nature of open angle glaucoma at a personalized level.

\subsubsection{Obesity}

The rising prevalence of obesity in the United States continues to reach epidemic levels. ${ }^{57-58}$ Correlational analysis from several epidemiological studies presents conflicting data. ${ }^{59-61}$ To date, the precise relationship between obesity and glaucoma progression remains unclear. In one study, systemic changes associated with obesity and metabolic syndrome, such as insulin resistance and systemic hypertension, were shown to be positively correlated with IOP elevation, which is a risk factor for glaucoma development. ${ }^{61}$ It was hypothesized that high systemic blood pressure increases ultrafiltration of the aqueous humor, whereby increasing IOP. In a different retrospective study, primarily of ED individuals, increased BMI 
(body mass index) was shown to have neuroprotective effects against glaucoma progression. The study postulated that an increase in translaminar pressure, indicative of IOP and CSFP differences, damages the optic nerve and contributes to glaucomatous optic neuropathy. High CSFP may reduce translaminar pressure, which in turn reduces the risk of glaucoma. ${ }^{65-66}$ Results published by our research team agreed are congruent with findings in Berdahl et al. (2008). ${ }^{65-66}$ We showed that there was a negative correlation between IOP and OPP in overweight (BMI 25-30) and obese (BMI >30) patients; this relationship was not seen in patients with normal BMI $(<25) .{ }^{67}$ The variation in the results of previous publications further obscures the relationship between weight and POAG development.

Building upon previous studies on obesity and glaucoma progression, we analyzed our 5-years prospective study according to patient's weight. We observed statistically significant changes between patients of normal weight and obese patients from baseline to 5 years follow-up in the following parameters: temporal posterior short ciliary arteries peak systolic velocity $(p=0.0118)$, cup area $(p=0.0370)$, vertical CDR $(p=0.0365)$, macular thickness inner temporal $(p=0.0110)$ and cup volume $(p=0.0083)$. When the overall data was analyzed, without consideration of weight, the change in temporal posterior short ciliary arteries peak systolic velocity was not statistically significant. This suggests the necessity of analyzing epidemiological data with patient-specific factors to reveal their correlational relationship. Moreover, our result on the vertical CDR is varied from a prior publication by Pedro-Egbe et al. (2013), which showed no statistically significant correlation between vertical CDR and BMI. ${ }^{68}$ Moreover, the baseline BMI category (obese versus normal weight) was a predictive factor of glaucoma structural progression after five years $(p=0.0435)$. We speculate that factors, such as patient's racial ethnicity, diabetes, gender, weight, and age, may have contributed to the differences reported in previous studies.

Given the diverse results from these various studies, including results from our team, the relationship between obesity and glaucoma progression remains unsettled. To clarify the effect of obesity on POAG development and progression, further advancement in current mathematical models is necessary to integrate multiple demographic parameters to predict disease progression.

\subsubsection{Age}

Several longitudinal population-based studies have shown that age is a risk factor for the development of POAG in healthy subjects. . $2,69-71$ The risk of developing glaucoma in subjects who were one year older at baseline was higher by $4 \%$ in the Barbados Incidence Study of Eye Diseases and by $6 \%$ in the Rotterdam Eye Study. ${ }^{42,69}$ In the Melbourne Visual Impairment Project subjects aged 40-49 years old at baseline had a 12 -fold lower five-year risk of developing POAG compared to subjects with an age of 70-79 years old at baseline. ${ }^{71}$ Older age is also a predictive baseline factor associated with the development of POAG in patients with ocular 
hypertension, as demonstrated in the Ocular Hypertension Treatment Study and in the European Glaucoma Prevention Study. ${ }^{72-73}$ Finally, results from the Early Manifest Glaucoma Trial have shown that older age at baseline is also a prognostic factor for the progression of POAG. ${ }^{74}$

Knowing the importance of the patient's age not only as a risk factor for the onset of glaucoma but also as a prognostic factor for the disease progression, the role of retrobulbar blood flow in patients with POAG of different ages over a five-year period was investigated in our pilot analysis. The peak systolic velocity $(p=0.0140)$ and the end diastolic velocity $(p=0.0373)$ of the ophthalmic artery and the end diastolic velocity of the temporal posterior ciliary arteries $(p=0.0086)$ were found to be statistically different between subjects aged $\geq 65$ compared to subjects aged $<65$ as predictive factors of functional progression. Furthermore, we found that baseline age was a predictive factor of functional glaucoma progression after five years $(p=0.0098)$.

As shown by the aforementioned large population studies and by the recent findings of our research group, age is an important factor in the natural history of glaucoma, playing a well-established role in the disease development and advancement. The formulation of a dynamic mathematical model including subjects' age is clearly needed to allow clinicians to have a tailor approach in the diagnosis and treatment of their glaucomatous patients.

\section{Conclusion}

Our review of previous research shows that POAG patients of varying race, diabetic status, gender, obesity, and age differ in terms of their initial presentation and subsequent progression. The manner in which these systemic and ocular physiological parameters change, both in terms of structure and function, are highly variable in disease progression. Additional studies will allow the creation of a dynamic model needed to understand the highly complex interactions between each of the aforementioned variables, as well as their role in the pathogenesis and natural history of glaucoma.

Mathematical modeling in medicine is often utilized for its intrinsic ability to use the predictive values of known risk factors to forecast the development of certain diseases. Such algorithms have been employed to characterize glaucoma progression based on biomechanical changes of the eye and its ocular hemodynamics. However, efforts to quantify the complex nature of these systemic factors to provide comprehensive modeling of glaucoma development and progression are incomplete and ongoing. Based on our summarized results in this review, we advocate for the need to establish mathematical modeling so that the predictive values of known risk factors can be used to correctly identify patients with the highest risk of developing glaucoma. This comprehensive dynamic model will 
include vital demographic characteristics, such as race, diabetic status, gender, obesity, and age that will allow physicians the ability to confidently provide clear, individualized, evidence based approach for each of their patients.

\section{Acknowledgement}

Supported in part by an NIH grant: 1R21EY022101-01A1, ADA Grant 1-12-IN-20, and an unrestricted grant from Research to Prevent Blindness, Inc.

\section{References}

1. Leske MC. Open-angle glaucoma: an epidemiological overview. Ophthalmic Epidemiol 2007;14(4):166-172. Available from: http://www.diseaseinfosearch.org/result/3065 PubMed PMID: 17896292. doi: 10.1080/09286580701501931.

2. Kingman S. Glaucoma is second leading cause of blindness globally. Bull World Health Organ 2004;82(11):887-8.

3. Cook C, Foster P. Epidemiology of glaucoma: what's new?. Can J Ophthalmol 2012;47(3):223-226. Available from: http://www.diseaseinfosearch.org/result/3065 PubMed PMID: 22687296. doi: 10.1016/j.jcjo.2012.02.003.

4. Grewe R. [The history of glaucoma].. Klin Monbl Augenheilkd 1986;188(2):167-169. Available from: http://www.diseaseinfosearch.org/result/3065 PubMed PMID: 3520122. doi: 10.1055/s-20081050606.

5. Leske MC, Heijl A, Hyman L, Bengtsson B, Dong L, Yang Z. Predictors of long-term progression in the early manifest glaucoma trial.. Ophthalmology 2007;114(11):1965-1972. Available from: http:// www.scholaruniverse.com/ncbi-linkout?id=17628686 PubMed PMID: 17628686. doi: 10.1016/j. ophtha.2007.03.016.

6. Caprioli J, Coleman AL. Intraocular pressure fluctuation a risk factor for visual field progression at low intraocular pressures in the advanced glaucoma intervention study.. Ophthalmology 2008 Feb;115(7):1123-1129. Available from: http://www.scholaruniverse.com/ncbi-linkout?id=18082889 PubMed PMID: 18082889. doi: 10.1016/j.ophtha.2007.10.031.

7. Caprioli J, Coleman AL. Blood flow in glaucoma discussion; blood pressure, perfusion pressure, and glaucoma. Am J Ophthalmol 2010;149(5):704-712. Available from: http://www.diseaseinfosearch. org/result/3065 PubMed PMID: 20399924. doi: 10.1016/j.ajo.2010.01.018.

8. Danias J, Podos SM. Comparison of glaucomatous progression between untreated patients with normal-tension glaucoma and patients with therapeutically reduced intraocular pressures. The effectiveness of intraocular pressure reduction in the treatment of normal-tension glaucoma. Am J Ophthalmol 1999;127(5):623-5.

9. Ehrnrooth P, Puska P, Lehto I, et al. Progression of visual field defects and visual loss in trabeculectomized eyes. Graefes Arch Clin Exp Ophthalmol 2005;243(8):741-747. Available from: https://www. researchgate.net/publication/e/pm/15700183?ln_t=p\&ln_o=linkout PubMed PMID: 15700183. doi: 10.1007/s00417-004-1088-3.

10. Tielsch JM, Sommer A, Katz J, et al. Racial variations in the prevalence of primary open angle glaucoma, the baltimore eye survey. JAMA 1991 Jul;266(3):369-74. Available from: http://www.scholaruniverse. com/ncbi-linkout?id=2056646 PubMed PMID: 2056646. doi: 10.1001/jama.1991.03470030069026.

11. Chung HS, Harris A, Kagemann L, Martin B. Peripapillary retinal blood flow in normal tension glaucoma.. Br J Ophthalmol 1999;83(4):466-469. Available from: http://bjo.bmj.com/cgi/pmidlookup?view=long\&pmid=10434872 PubMed PMID: 10434872. doi: 10.1136/bjo.83.4.466. 
12. Harris A, Sergott RC, Spaeth. GL et al. Color Doppler analysis of ocular vessel blood velocity in normal-tension glaucoma. Am J Ophthalmol 1994;118(5):642-9. Available from: http://linkinghub. elsevier.com/retrieve/pii/S0002939414765791 doi: 10.1016/S0002-9394(14)76579-1.

13. Coleman AL, Caprioli J. The logic behind target intraocular pressure. Am J Ophthalmol 2009;147(3):379-80. Available from: http://linkinghub.elsevier.com/retrieve/pii/S0002939408008854 doi: 10.1016/j.ajo.2008.10.027.

14. Harris A, Guidoboni G, Arciero JC, et al. Ocular hemodynamics and glaucoma: The role of mathematical modeling. Eur J Ophthalmol 2013 Mar;23(2):139-46. doi: 10.5301/ejo.5000255.

15. Karpinich NO, Caron KM. Schlemm's canal: more than meets the eye, lymphatics in disguise. The Journal of Clinical Investigation. 20142014 Jul;124(9):3701-3703. Available from: http://europepmc. org/abstract/MED/25061871 PubMed PMID: 25061871. doi: 10.1172/JCI77507.

16. Truong TN, Li H, Hong Y, Chen L. Novel characterization and live imaging of Schlemm's canal expressing Prox-1.. PLoS One 2014 May;9(5):579-84. Available from: http://dx.plos.org/10.1371/journal. pone.0098245 PubMed PMID: 24827370. doi: 10.1371/journal.pone.0098245.

17. Kansky JJ. Clinical ophthalmology: A systemic approach. Seventh edition. Elsevier; 2011.

18. Harris A, Guidoboni G, Arciero JC, et al. Ocular hemodynamics and glaucoma: The role of mathematical modeling. Eur J Ophthalmol 2013;23(2):139-146. Available from: http://www.eur-j-ophthalmol. com/article/ocular-hemodynamics-and-glaucoma--the-role-of-mathematical-modeling PubMed PMID: 23413108. doi: 10.5301/ejo.5000255.

19. Norman RE, Flanagan JG, Sigal IA, Rausch SMK, Tertinegg I, Ethier, C. Ross . Finite element modeling of the human sclera: Influence on optic nerve head biomechanics and connections with glaucoma. Experimental Eye Research 2011;93(1):4-12. Available from: http://linkinghub.elsevier.com/retrieve/ pii/S001448351000309X PubMed PMID: 20883693. doi: 10.1016/j.exer.2010.09.014.

20. Dongqi H, Zeqin R. A biomathematical model for pressure-dependent lamina cribrosa behavior. J Biomech 1999;32(6):579-584. Available from: http://linkinghub.elsevier.com/retrieve/pii/ S0021929099000251 PubMed PMID: 10332621. doi: 10.1016/S0021-9290(99)00025-1.

21. Bellezza AJ, Hart RT, Burgoyne CF. The optic nerve head as a biomechanical structure: initial finite element modeling.. Invest Ophthalmol Vis Sci 2000;41(10):2991-3000. Available from: http://www. scholaruniverse.com/ncbi-linkout?id=10967056 PubMed PMID: 10967056.

22. Sigal IA, Flanagan JG, Tertinegg I, Ethier CR. Finite element modeling of optic nerve head biomechanics. Invest Ophthalmol Vis Sci 2004;45(12):4378-4387. Available from: http://iovs.arvojournals. org/article.aspx?doi=10.1167/iovs.04-0133 PubMed PMID: 15557446. doi: 10.1167/iovs.04-0133.

23. Yousefi S, Goldbaumn M, Balasubramanian M, et al. Glaucoma progression detection using structural retinal nerve fiber layer measurements and functional visual field points. IEEE Trans Biomed Eng 2014;61(4):1143-1154. Available from: http://europepmc.org/abstract/MED/24658239 PubMed PMID: 24658239. doi: 10.1109/TBME.2013.2295605.

24. Newson T, El-Sheikh A. "Mathematical modeling of the biomechanic of the laimina cribrosa under elevated intraocular pressures. " J Biomech Eng 2006;128(4):496-504. Available from: http://Biomechanical.asmedigitalcollection.asme.org/article.aspx?articleid=1415626 doi: 10.1115/1.2205372.

25. Leske MC, Connell AM, Schachat AP, et al. The Barbados eye study, prevalence of open angle glaucoma. Arch Ophthalmol 1994;112(6):821-9. Available from: http://archopht.jamanetwork.com/ article.aspx?doi=10.1001/archopht.1994.01090180121046 PubMed PMID: 8002842. doi: 10.1001/ archopht.1994.01090180121046.

26. Mason RP, Kosoko O, Wilson MR, et al. National survey of the prevalence and risk factors of glaucoma in St. Lucia, West Indies. Part I. Prevalence findings. Ophthalmology 1989;96(9):1363-1368. Available from: http://linkinghub.elsevier.com/retrieve/pii/S0161642089327084 doi: 10.1016/S01616420(89)32708-4.

27. Rotchford AP, Kirwan JF, Muller MA, et al. Temba glaucoma study: A population-based crosssectional survey in urban South Africa. Ophthalmology 2003;110(2):376-82. Available from: http://linkinghub. elsevier.com/retrieve/pii/S0161642002015683 doi: 10.1016/S0161-6420(02)01568-3. 
28. Gordon MO, Beiser JA, Brandt JD, Heuer DK, Higginbotham EJ, Johnson CA, et al. The Ocular Hypertension Treatment Study: baseline factors that predict the onset of primary open-angle glaucoma.. Arch Ophthalmol 2002;120(6):714-720. Available from: http://www.scholaruniverse.com/ncbi-linkout?id=12049575 PubMed PMID: 12049575 . doi: 10.1167/iovs.14-15719.

29. Martin MJ, Sommer A, Gold EB, Diamond EL. Race and primary open-angle glaucoma.. Am J Ophthalmol 1985 Apr;99(4):383-387. Available from: http://www.diseaseinfosearch.org/result/3065 PubMed PMID: 3985075. doi: 10.1001/archophthalmol.2010.49.

30. Racette L, Liebmann JM, Girkin CA, Zangwill LM, Jain S, Becerra LM, et al. African Descent and Glaucoma Evaluation Study (ADAGES): III. Ancestry differences in visual function in healthy eyes.. Arch Ophthalmol 2010;128(5):551-559. Available from: http://europepmc.org/abstract/MED/20457975 PubMed PMID: 20457975. doi: 10.1001/archophthalmol.2010.58.

31. Racette L, Wilson MR, Zangwill LM, et al. Primary open-angle glaucoma in blacks: A review. Surv Ophthalmol 2003;48(3):295-313. Available from: http://www.scholaruniverse.com/ncbi-linkout?id=12745004 PubMed PMID: 12745004 . doi: 10.1001/archophthalmol.2009.187.

32. Girkin CA, Nievergelt CM, Kuo JZ, Maihofer AX, Huisingh C, Liebmann JM, et al. Biogeographic Ancestry in the African Descent and Glaucoma Evaluation Study (ADAGES): Association With Corneal and Optic Nerve Structure.. Invest Ophthalmol Vis Sci 2015 Mar;56(3):2043-2049. Available from: http://europepmc.org/abstract/MED/25744975 PubMed PMID: 25744975. doi: 10.1167/iovs.1415719.

33. Girkin CA, Sample PA, Liebmann JM, Jain S, Bowd C, Becerra LM, et al. African Descent and Glaucoma Evaluation Study (ADAGES): II. Ancestry differences in optic disc, retinal nerve fiber layer, and macular structure in healthy subjects.. Arch Ophthalmol 2010;128(5):541-550. Available from: http://europepmc.org/abstract/MED/20457974 PubMed PMID: 20457974. doi: 10.1001/archophthalmol.2010.49.

34. Moore GH, Bowd C, Medeiros FA. African Descent and Glaucoma Evaluation Study (ADAGES): Asymmetry of structural measures in normal participants. J Glaucoma 2015 Feb;2013(1):22-2. doi: 10.4239/wjd.v6.i1.92.

35. Sample PA, Girkin CA, Zangwill LM, Jain S, Racette L, Becerra LM, et al. The African Descent and Glaucoma Evaluation Study (ADAGES): design and baseline data.. Arch Ophthalmol 2009;127(9):11361145. Available from: http://europepmc.org/abstract/MED/19752422 PubMed PMID: 19752422. doi: 10.1001/archophthalmol.2009.187.

36. Siesky B, Harris A, Racette L, Abassi R, Chandrasekhar K, Tobe LA, et al. Differences in ocular blood flow in glaucoma between patients of African and European descent.. J Glaucoma 2015;24(2):117121. Available from: http://content.wkhealth.com/linkback/openurl?sid=WKPTLP:landingpage\&an=00061198-201502000-00005 PubMed PMID: 23807346. doi: 10.1097/ IJG.0b013e31829d9bb0.

37. Kanakamedala P, Harris A, Siesky B, Tyring A, Muchnik M, Eckert G, et al. Optic nerve head morphology in glaucoma patients of African descent is strongly correlated to retinal blood flow. Br J Ophthalmol 2014 Jun;98(11):1551-1554. Available from: http://europepmc.org/abstract/MED/24964797 PubMed PMID: 24964797. doi: 10.1136/bjophthalmol-2013-304393.

38. Sayin N, Kara N, and Pekel G . Ocular complications of Diabetes Mellitus. World J Diabetes 2015 Feb;6(1):92-108. Available from: http://www.wjgnet.com/1948-9358/full/v6/i1/92.htm doi: 10.4239/ wjd.v6.i1.92.

39. Newman-Casey PA, Talwar N, Nan B, et al. The relationship between components of metabolic syndrome and open-angle glaucoma. Ophthalmology 2011;118(7):1318-1016. Available from: http://europepmc.org/abstract/MED/21481477 PubMed PMID: 21481477. doi: 10.1016/j. ophtha.2010.11.022.

40. Chopra V, Varma R, Francis BA, et al. Type 2 Diabetes Mellitus and the risk of open-angle glaucoma the Los Angeles Latino Eye Study. Ophthalmology 2008;115(2):227-232. Available from: http:// www.scholaruniverse.com/ncbi-linkout?id=17716734 PubMed PMID: 17716734. doi: 10.1016/j. ophtha.2007.04.049. 
41. Zhou M, Wang W, Huang W. Diabetes Mellitus as a risk factor for open-angle glaucoma: A Systematic Review and Meta-Analysis. PloS One. 2014 Aug 2006;19(9):10-1371.

42. Voogd, S. de, , Ikram MK, Wolfs RC, et al. Is Diabetes Mellitus a risk factor for open-angle glaucoma? The Rotterdam Study. Ophthalmology 2006;113(10):1827-31. Available from: http://linkinghub. elsevier.com/retrieve/pii/S0161642006006920 doi: 10.1016/j.ophtha.2006.03.063.

43. Ozdamar Y, Cankaya B, Ozalp S. Is There a correlation between Diabetes Mellitus and central corneal thickness. J Glaucoma 1992;2010:19-9.

44. Kanamori A, Nakamura M, Mukuno H, Maeda H, Negi A. Diabetes has an additive effect on neural apoptosis in rat retina with chronically elevated intraocular pressure. Curr Eye Res 2004;28(1):47-54. Available from: https://www.researchgate.net/publication/e/pm/14704913?ln_t=p\&ln_o=linkout PubMed PMID: 14704913. doi: 10.1076/ceyr.28.1.47.23487.

45. Halilovic EA, Ljaljevic S, Alimanovic I, et al. Analysis of the Influence of Type of Diabetes Mellitus on the Development and Type of Glaucoma. Medical Archives 2015;69(1):34-7. Available from: http:// www.scopemed.org/?mno=180720 PubMed PMID: 25870475. doi: 10.5455/medarh.2015.69.34-37.

46. Shoshani Y, Harris A, Shoja MM, et al. Impaired ocular blood flow regulation in patients with openangle glaucoma and diabetes. Clin Experiment Ophthalmol 2012;40(7):697-705. Available from: http:// doi.wiley.com/10.1111/j.1442-9071.2012.02778.x doi: 10.1111/j.1442-9071.2012.02778.x.

47. Mitchell P, Smith W, Attebo K, Healey PR. Prevalence of open-angle glaucoma in Australia. The Blue Mountains Eye Study.. Ophthalmology 1996;103(10):1661-1669. Available from: http://linkinghub.elsevier.com/retrieve/pii/S0161642096304491 PubMed PMID: 8874440. doi: 10.1016/S01616420(96)30449-1.

48. Rudnicka AR, Mt-Isa S, Owen CG, Cook DG, Ashby D. Variations in primary open-angle glaucoma prevalence by age, gender, and race: a Bayesian meta-analysis.. Invest Ophthalmol Vis Sci 2006;47(10):4254-4261. Available from: http://www.scholaruniverse.com/ncbi-linkout?id=17003413 PubMed PMID: 17003413. doi: 10.1167/iovs.06-0299.

49. Khan HA, Leibowitz HM, Ganley JP, et al. The Framingham Eye Study. II. Association of ophthalmic pathology with single variables previously measured in the Framingham Heart Study. Am J Epidemiol 1977;106(1):33-41. Available from: https://www.nlm.nih.gov/medlineplus/cataract.html PubMed PMID: 141882.

50. Klein BE, Klein R, Sponsel WE, Franke T, Cantor LB, Martone J, et al. Prevalence of glaucoma. The Beaver Dam Eye Study.. Ophthalmology 1992;99(10):1499-1504. Available from: http://www. scholaruniverse.com/ncbi-linkout?id=1454314 PubMed PMID: 1454314. doi: 10.1016/S01616420(92)31774-9.

51. Ustymowicz A, Mariak Z, Weigele J, Lyson T, Kochanowicz J, Krejza J. Normal reference intervals and ranges of side-to-side and day-to-day variability of ocular blood flow Doppler parameters. Ultrasound Med Biol 2005;31(7):895-903. Available from: https://www.researchgate.net/publication/e/pm/15972195?ln_t=p\&ln_o=linkout PubMed PMID: 15972195. doi: 10.1016/j.ultrasmedbio.2005.03.013.

52. Marjanovic I, Marjanovic M, Gvozdenovic R, et al. Retrobulbar heodynamic parameters in men and women with open angle glaucoma. Voinosanit Pregl 2014;71(12):1128-31. Available from: http:// www.doiserbia.nb.rs/Article.aspx?ID=0042-84501412128M doi: 10.2298/VSP1412128M.

53. Harris-Yitzhak M, Harris A, Ben-Refael Z, et al. Estrogen-replacement therapy: effects on retrobulbar hemodynamics. Am J Ophthalmol 2000;129(5):623-628. Available from: http://www.scholaruniverse. com/ncbi-linkout?id=10844054 PubMed PMID: 10844054. doi: 10.1016/S0002-9394(99)00468-7.

54. Siesky B, Harris A, Kheradiya N, Ehrlich R, Klaas C, Kaplan B, et al. The effects of raloxifene hydrochloride on ocular hemodynamics and visual function. Int Ophthalmol 2008 Apr;29(4):225-230. Available from: http://www.scholaruniverse.com/ncbi-linkout?id=18427730 PubMed PMID: 18427730. doi: 10.1007/s10792-008-9224-4.

55. Wang S, Xu L, Wang Y, Wang Y, Jonas JB. Retinal vessel diameter in normal and glaucomatous eyes: the Beijing eye study.. Clin Experiment Ophthalmol 2007;35(9):800-807. Available from: https:// 
www.nlm.nih.gov/medlineplus/glaucoma.html PubMed PMID: 18173406. doi: 10.1111/j.14429071.2007.01627.x.

56. Wong TY, Klein R, Klein BEK, Meuer SM, Hubbard LD. Retinal vessel diameters and their associations with age and blood pressure.. Invest Ophthalmol Vis Sci 2003;44(11):4644-4650. Available from: http://iovs.arvojournals.org/article.aspx?doi=10.1167/iovs.03-0079 PubMed PMID: 14578380. doi: 10.1167/iovs.03-0079.

57. Ogden C, Carroll M, Kit B, et al. Prevalence of childhood and adult obesity in the United States, 2011-2012. JAMA 2014 Feb;311(8):806-14. Available from: http://jama.jamanetwork.com/article. aspx?doi=10.1001/jama.2014.732 doi: 10.1001/jama.2014.732.

58. Finkelstein EA, Khavjou OA, Thompson H, Trogdon JG, Pan L, Sherry B, et al. Obesity and severe obesity forecasts through 2030.. Am J Prev Med 2012;42(6):563-570. Available from: http://linkinghub.elsevier.com/retrieve/pii/S0749379712001468 PubMed PMID: 22608371. doi: 10.1016/j. amepre.2011.10.026.

59. Yoshida M, Ishikawa M, Karita K, et al. Association of blood pressure and body mass index with intraocular pressure in middle-aged and older Japanese residents: a cross-sectional and longitudinal study. Acta Med Okayama 2015;68(1):27-34. Available from: http://www.lib.okayama-u.ac.jp/www/ acta/pdf/68_1_27.pdf PubMed PMID: 24553486. doi: 10.1167/iovs.08-2228.

60. Geloneck MM, Crowell EL, Wilson EB, Synder BE, Chuang AZ, Baker LA, et al. Correlation between intraocular pressure and body mass index in the seated and supine positions.. J Glaucoma 2015;24(2):130-134. Available from: https://www.nlm.nih.gov/medlineplus/obesity.html PubMed PMID: 24247996. doi: 10.1097/01.ijg.0000435775.05032.87.

61. Sw OH, Lee $\mathrm{S}$, Park $\mathrm{C}$, et al. Elevated intraocular pressure is associated with insulin resistance and metabolic syndrome. Diabetes Metab Res Rev 2005;21(5):434-40.

62. Gasser P, Stümpfig D, Schötzau A, Ackermann-Liebrich U, Flammer J. Body mass index in glaucoma.. J Glaucoma 1999;8(1):8-11. Available from: http://www.diseaseinfosearch.org/result/3065 PubMed PMID: 10084268.

63. Asrani S, Samuels B, Thakur M, Santiago C, Kuchibhatla M. Clinical profiles of primary open angle glaucoma versus normal tension glaucoma patients: a pilot study.. Curr Eye Res 2011;36(5):429435. Available from: http://www.diseaseinfosearch.org/result/3065 PubMed PMID: 21501076. doi: 10.3109/02713683.2011.559563.

64. Kang JH, Loomis SJ, Rosner BA, et al. Comparison of risk factor profiles for primary open-angle glaucoma subtypes defined by pattern of visual field loss: a prospective study. Invest Ophthalmolmol Vis Sci 2015;56(4):2439-48. Available from: http://europepmc.org/abstract/MED/25758813 PubMed PMID: 25758813. doi: 10.1167/iovs.14-16088.

65. Berdahl JP, Allingham RR, Johnson DH. Cerebrospinal fluid pressure is decreased in primary open-angle glaucoma. Ophthalmology 2008;115(6):763-8. Available from: http://linkinghub.elsevier. com/retrieve/pii/S016164200800064X doi: 10.1016/j.ophtha.2008.01.013.

66. Berdahl JP, Fautsch MP, Stinnet SS, et al. Intracranial pressure in primary open angle glaucoma, normal tension glaucoma, and ocular hypertension: a case-control study. Invest Ophthalmol Vis Sci 2008;49(12):5412-8. Available from: http://europepmc.org/abstract/MED/18719086 PubMed PMID: 18719086. doi: 10.1167 /iovs.08-2228.

67. Ngo S, Harris A, Sieksy BA, et al. Blood pressure, ocular perfusion pressure, and body mass index in glaucoma patients. Eur J Ophthal 2013;23(5):664-9. Available from: http://www.eur-j-ophthalmol. com/article/blood-pressure--ocular-perfusion-pressure--and-body-mass-index-in-glaucoma-patients doi: 10.5301/ejo.5000257.

68. Pedro-Egbe $C$ and Awoyesuku $E$. The relationship between vertical cup-disc ratio and body mass index in Port Harcourt, Nigeria. Niger J Clin Pract 2013;16(4):517-20. Available from: http://www. njcponline.com/text.asp?2013/16/4/517/116904 PubMed PMID: 23974750. doi: 10.4103/1119- 
3077.116904.

69. Leske MC, Wu SY, Hennis A et al. Risk factors for incident open-angle glaucoma: The Barbados Eye Studies. Ophthalmology 2008;115(1):85-93. Available from: http://linkinghub.elsevier.com/retrieve/ pii/S0161642007002424 doi: 10.1016/j.ophtha.2007.03.017.

70. Müskens RPHM, de Voogd S, Wolfs RCW, Witteman JCM, Hofman A, de Jong PTVM, et al. Systemic antihypertensive medication and incident open-angle glaucoma.. Ophthalmology 2007;114(12):22212226. Available from: http://www.scholaruniverse.com/ncbi-linkout?id=17568677 PubMed PMID: 17568677. doi: 10.1016/j.ophtha.2007.03.047.

71. Le A, Mukesh BN, McCarty CA, Taylor HR. Risk factors associated with the incidence of open-angle glaucoma: the visual impairment project.. Invest Ophthalmol Vis Sci 2003;44(9):3783-3789. Available from: http://iovs.arvojournals.org/article.aspx?doi=10.1167/iovs.03-0077 PubMed PMID: 12939292. doi: 10.1167/iovs.03-0077.

72. Kass MA, Heuer DK, Higginbotham EJ, Johnson CA, Keltner JL, Miller JP, et al. The Ocular Hypertension Treatment Study: a randomized trial determines that topical ocular hypotensive medication delays or prevents the onset of primary open-angle glaucoma.. Arch Ophthalmol 2002;120(6):701713. Available from: http://www.scholaruniverse.com/ncbi-linkout?id=12049574 PubMed PMID: 12049574.

73. Miglior S, Zeyen T, Pfeiffer N, Cunha-Vaz J, Torri V, Adamsons I. Results of the European Glaucoma Prevention Study.. Ophthalmology 2005;112(3):366-375. Available from: http://www.diseaseinfosearch.org/result/3065 PubMed PMID: 15745761. doi: 10.1016/j.ophtha.2004.11.030.

74. Heijl A, Leske MC, Bengtsson B, Hyman L, Bengtsson B, Hussein M. Reduction of intraocular pressure and glaucoma progression: results from the Early Manifest Glaucoma Trial.. Arch Ophthalmol 2002;120(10):1268-1279. Available from: http://archopht.jamanetwork. com/article.aspx?doi=10.1001/archopht.120.10.1268 PubMed PMID: 12365904. doi: 10.1001/ archopht.120.10.1268. 